\title{
AUDIT \\ The use of clozapine in South Manchester
}

\author{
Alice Seabourne and Christopher S. Thomas
}

\begin{abstract}
We describe a survey examining the use of clozapine in South Manchester since 1990. The aims were to determine the patient characteristics, type of illness, response to treatiment and recording of this informafion. The case-notes of the first 25 patients to recelve clozapine between 1990 and 1992 were audited. Guidelines about who should recelve this ding and what objective asecesments should be performed were ogreed by the consultant group. The cudit demonstrated that 24 patients suttered from chronic schizophrenia which had folled to respond to convenfional neuroleptics. Routine mental state examinations were regularty pertormed but objective assessments using standardised rating scales were employed infrequentty. Sixteen out of 25 improved on clozepine but at the end of 1992 only ten subjects were still recelving this drug. The majority had been discontinued because of side effects.

It is well recognised that clozapine can be superior to conventional neuroleptics in treatment resistant schizophrenia (Kane et al, 1988; Mortimer, 1991). This survey was prompted by concerns from the pharmacy department of the University Hospital of South Manchester of an exponential increase in expenditure on clozapine and a need to justify to managers that the medication was being used cautiously and appropriately. It was agreed that clozapine should be offered only to those patients with chronic schizophrenia who had failed to respond over at least a six month period to two or more different neuroleptics in moderate to high dosage.
\end{abstract}

\section{The study}

The notes and medication charts of all subjects who had or were currently taking clozapine between December 1990 and December 1992 were examined. Data were collected for sociodemographic details, legal status, type of lliness, previous medication, response to treatment and side effects if any from clozapine.

\section{Findings}

Twenty-five patients were started on clozapine by eight consultant psychiatrists during the two years. There were 20 males and five females with mean age 35.5 (s.d. $=13.9$ ) and $38.2($ s.d. $=11.9$ ) years respectively. All had a chronic psychotic illness (24 schizophrenic and one manicdepressive). The mean age of onset of illness was 21.8 (s.d.=6.3) years, with a mean of 7.4 (s.d.=4.4) admissions and a total length of time spent in hospital of 41.3 (s.d.=65.7) months. Seven were on section 3 of the Mental Health Act, 1983. All the patients with schizophrenia had not responded to at least three different neuroleptics prior to commencing clozapine (mean number of neuroleptics $=5.1, s . d=1.5$ ). The manicdepressive patient was treated with clozapine as she had developed neuroleptic malignant syndrome with two different neuroleptics in the past (Burrell et al, 1991).

The notes were scrutinised for the use of objective rating scales of the mental state examination and changes in mental state. The brief psychiatric rating scale (BPRS) was performed on one patient prior to commencing treatment and on five during treatment with clozapine (Lukoff et al, 1986). The mental state improved in 16 subjects but was unchanged in nine.

At the end of 1992, 15 subjects had ceased treatment with clozapine. The reasons for discontinuation were severe side effects $(n=8)$, nonresponders $(n=2)$, problems with compliance $(n=3)$, and concurrent intravenous drug use $(n=1)$. In one subject the reason for discontinuing the clozapine was not clear. The side effects included hypersalivation $(n=5)$, sedation $(n=3)$, grand mal fits $(n=2)$, myoclonic jerks $(n=1)$, vomiting $(n=2)$, neutropaenia $(n=1)$, neuroleptic malignant syndrome $(n=1)$, acute confusional state with cognitive impairment $(n=1)$, slurred speech $(n=1)$, benign hyperthermia $(n=1)$, dry mouth $(n=1)$, weight gain $(n=1)$, constipation $(n=1)$, diarrhoea $(n=1)$, hypotension $(n=1)$ and urinary incontinence $(n=1)$. Four had eplleptiform changes on the EEG. The decision to continue or discontinue treatment was made by each consultant led team.

The mean daily dose of clozapine was 445 (s.d.=267) $\mathrm{mg} /$ day for patients who responded to clozapine, 633 (s.d.=301) $\mathrm{mg} /$ day for 
non-responders and $356($ s.d.=191) $\mathrm{mg} /$ day for subjects who developed side effects (differences not statistically significant). The mean durations of treatment were 15.5, 6.3 and 5.3 months for the respective groups.

At the end of 1992, seven men and three women were taking clozapine. All demonstrated significant improvements in mental state or behaviour; and seven were living in the community.

\section{Comment}

The prescription of clozapine was used almost exclusively for patients with chronic schizophrenic illness, who had been ill on average at least 13 years. They had multiple and often long previous admissions. All had falled to respond to on average, at least five different neuroleptics, demonstrating that clozapine was only being used where other treatments had failed.

Routine use of objective ratings of the metal state was minimal. This aspect of assessment together with accurate documentation of changes in mental state or behaviour could be improved as such information can be very important when trying to decide whether patients have responded to clozapine. The importance of clear recording of the BPRS or changes in the mental state is crucial especially when Meltzer et al (1989) have demonstrated continued improvements between six and 12 months of treatment. These small improvements may be missed, particularly if there are changes of junior medical staff or the patient is transferred to another team, as often happens when patients are transferred to a rehabilitation service. Another way of improving objectivity would be the systematic peer review of a patient's response to treatment to ensure that patients who receive clozapine are benefiting from the treatment.

Although $64 \%$ of patients treated with clozapine were recorded to have improvements in mental state, serious side effects leading to discontinuation of medication developed in 32\%. King \& Mills (1993) found that 21\% (5 out of 24) of subjects suffering from chronic schizophrenia were withdrawn from clozapine treatment because of non-response or side effects. Overall in our study $40 \%(n=10)$ remained on clozapine, $44 \%(n=11)$ developed significant side effects or did not respond, and $16 \%(n=4)$ did not comply with treatment. The Clozapine Study Group (1993) reported a similar proportion of subjects, $48 \%$ ( 26 out of 54), who were able to tolerate clozapine. The high proportion of patients who discontinued treatment probably reflected a combination of one or more of the following factors: the potentially toxic nature of clozapine; the use of moderately high doses; and clinicians becoming familiar with the drug and its side effects.

In South Manchester which has a population of approximately 188,000 , if the one year prevalence of schizophrenia is estimated to be $0.3-0.4$ per 1,000 then one might expect that there would be between 564 and 752 subjects per year suffering from schizophrenia, of whom at least ten to 20\% (56-150) might be considered to be resistant to conventional neuroleptics. Currently clozapine has only been offered to a minority of patients suffering from treatment resistant schizophrenia in South Manchester. Managers have agreed to increase the current number of patients to receive clozapine from ten at the end of 1992 to 15 for the 1993 financial year. It will be important to ensure that the most effective use of this scarce resource is maximised and a fair system of allocation developed over the continuing months. Representations will also be made to purchasers to increase the funding arrangements for the prescription of clozapine. The survey will be repeated in 12 months and the progress of those subjects who falled to respond or were withdrawn from clozapine will be monitored.

\section{References}

Burreul, M. F., Fewster, C. Szabadi, E. \& Cashman, M. (1991) Clozapine-treated NMS. Brttish Journal of Psychlatry. 168, 577.

CLOzAPINE STUDY GROUP (1993) The safety and efficacy of clozapine in severe treatment-resistant schizophrenic patients in the UK. Brttish Journal of Psychiatry. 163, 150-154.

KANE, J.. HONIGFel, G., SINGer, J. \& MELTZER, H. Y. (1988) Clozapine for treatment resistant schizophrenia: a double blind comparison with chlorpromazine. Archives of General Psychiatry. 46, 789-96.

KnNG, D. J. \& Mnus, P. J. (1993) Clozapine: the Holywell experience with the first 24 patients. Irtsh Journal of Psychological Medictine, 10, 30-34.

LUKOFf. D., NeUChterLein, K. H. \& VentuRA, J. (1986) Manual for Expanded Brief Psychtatric Rating Scale (BPRS). Schizophrenia Bulletin, 12, 594-602.

Meltzar, H. Y., BAstan, B., Young KwON, K., RAMmez, L. F. et al (1989) A prospective study of clozapine in treatmentresistant schizophrenic patients. Psychopharmacology. 89. (Suppl.), 568-572.

MORTIER, A. M. (1991) Clozapine and schizophrenia. Schtzophrenia Monitor, 1, 1-4.

Alice Seabourne, Senior House Officer in Psychiatry: and Christopher S. Thomas, Consultant Psychiatrist with a special interest in rehabilitation. Department of Psychiatry. Untuersity Hospital of South Manchester, Manchester M20 8LR 